\title{
EM BUSCA DA PROSÓDIA
}

INAUDÍVEL: A DURAÇÃO

MUSICAL COMO PISTA DA

CONSTITUIÇÃO DAS FRASES

ENTOACIONAIS E DOS

ENUNCIADOS PROSÓDICOS

NAS CANTIGAS DE SANTA

\section{MARIA}

\author{
Gladis MASSINI-CAGLIARI ID \\ Faculdade de Ciências e Letras - Universidade Estadual Paulista (UNESP)
}

\section{๘}

OPEN ACCESS

EDITORES

- Miguel Oliveira, Jr. (UFAL)

- René Almeida (UFS)

AVALIADORES

- Beatriz Raposo (USP)

- Ester Scarpa (UNICAMP)

DATAS

- Recebido: 24/10/2020

- Aceito: 22/11/2020

- Publicado: 15/05/2021

\section{COMO CITAR}

MASSINI-CAGLIARI, Gladis (2021). Em busca da prosódia inaudível: a duração musical como pista da constituição das frases entoacionais e dos enunciados prosódicos nas Cantigas de Santa Maria. Cadernos de Linguística, v. 2, n. 1, p. 01-20.
RESUMO

O objetivo principal desta pesquisa é buscar pistas do agrupamento de constituintes prosódicos superiores, tais como a frase entoacional (I) e o enunciado prosódico $(U)$, a partir da consideração da música que acompanha as cantigas religiosas galego-portuguesas atribuídas a Afonso X (1221-1284), as Cantigas de Santa Maria. A metodologia de análise parte da observação da relação entre letra e música, verificando se elementos como duração e proeminência musical podem trazer pistas do processo de constituência prosódica no nível linguístico, ou seja, na marcação das fronteiras desses constituintes prosódicos superiores e da sua proeminência. Os resultados indicam uma preferência pela cumulação de fatores rítmicos e melódicos na marcação da saliência da frase entoacional (I). Com relação ao enunciado prosódico, o alongamento da duração, em nível musical, no final do constituinte, atinge tanto sílabas tônicas quanto átonas, revelando-se um indício confiável para a identificação do limite final de U e, portanto, de sua segmentação. 


\section{ABSTRACT}

The main objective of this work is searching for clues to superior prosodic constituents grouping, such as intonational phrase (I) and prosodic utterance $(U)$, departing from the consideration of the music that accompanies the religious Galician Portuguese cantigas, attributed to Alfonso X (1221-1284), the Cantigas de Santa Maria. The methodological support for the analysis is the observation of the relation between music and lyrics, in order to verify whether elements such as duration and musical prominence can bring clues to the process of prosodic constituency in the linguistic level, that is, in the process of marking the boundaries and the prominence of those superior prosodic constituents. The results indicate the preference for cumulating rhythmic and melodic factors in the process of marking the salience of intonational phrases (I). Relating to prosodic utterances, the duration lengthening at the end of the constituent, in musical level, reaches both stressed and unstressed syllables, revealing itself as a trustworthy index for the identification of U's final boundary and, therefore, of its segmentation.

PALAVRAS-CHAVE

Prosódia; Ritmo; Entoação; Música; Cantigas de Santa Maria.

\section{KEYWORDS}

Prosody; Rhythm; Intonation; Music; Cantigas de Santa Maria. 


\section{INTRODUÇÃO}

As perguntas que nortearam a presente investigação são as seguintes: Como fazer para "ouvir" os sons de uma época em que não havia gravador? E, mais, como perscrutar elementos prosódicos que não tinham contrapartida na escrita da época (como ritmo e entoação)? E como perceber a sua organização? Em outras palavras, como estudar a prosódia de um momento passado da língua?

Partindo dessas indagações gerais, este trabalho tem o objetivo de mostrar que procedimentos metodológicos que trabalham na interface com outras áreas possibilitam esta "audição" do passado, exemplificada a partir da análise do Português Arcaico (de agora em diante, PA), considerando o testemunho de cantigas medievais galegoportuguesas religiosas, as chamadas Cantigas de Santa Maria (de agora em diante, CSM), atribuídas ao rei sábio, Afonso X (1221-1284). Serão aqui consideradas as primeiras dez cantigas desse famoso cancioneiro religioso.

Como já mostramos em diversos trabalhos anteriores (especialmente, MassiniCagliari, 1999, 2015), a escolha de textos poéticos e a exploração de sua estrutura métrica traz pistas da silabação de palavras (ZUCARELLI, 2002; BIAGIONI, 2002; CANGEMI, 2014) e das proeminências em nível do verso que, por sua vez, se alicerçam em proeminências linguísticas. Os textos poéticos atuam também como ótimos "juízes", a partir das rimas possíveis e impossíveis, perfeitas e imperfeitas, da realização fonética de vogais (FONTE, 2010, 2014) e consoantes (GEMENTI, 2018) e do posicionamento do acento lexical (MASSINI-CAGLIARI, 1999, 2015). Por outro lado, a consideração da música das cantigas, combinada com a relação que tem com a "letra" (texto poético) que a acompanha, ajuda a elucidar questões de agrupamentos prosódicos em termos de constituintes superiores, principalmente com relação aos fenômenos rítmicos (MASSINICAGLIARI, 2008, 2010, 2011; COSTA, 2010).

A metodologia que será apresentada vem sendo desenvolvida pela autora desde sua tese de doutorado, em 1995, tendo sido progressivamente ampliada e aperfeiçoada, com a colaboração das pesquisas desenvolvidas no contexto do Grupo de Pesquisa Fonologia do Português: Arcaico \& Brasileiro, com o intuito de contribuir para o aprofundamento do conhecimento acerca da história do Português Brasileiro, sobretudo no que diz respeito a aspectos prosódicos (MASSINI-CAGLIARI, 2013). Neste contexto, o presente trabalho propõe uma aproximação entre as áreas de Linguística e Música, trabalhando na interface, entretanto situando-se a partir de um posicionamento bastante específico: trata-se de um estudo na área de Fonologia, cujo objetivo é perscrutar as contribuições possíveis da observação da estrutura musical das cantigas que acompanham os versos escritos na língua ancestral medieval do português para a determinação da prosódia linguística desse período histórico específico da língua. 
A aproximação entre Música e Linguística não é novidade em trabalhos desenvolvidos por linguistas, sobretudo nas áreas de Fonética e Fonologia, mas também em outras áreas. Jackendoff e Lerdahl (1980) e Lerdahl e Jackendoff (1983) são nomes bastante conhecidos para quem trabalha nessa interface, dado o seu interesse em comparar prosódia linguística e musical. No Brasil, vale a pena citar as contribuições de Raposo de Medeiros (2006, 2012), Raposo de Medeiros e Cummins (2014), Raposo de Medeiros e Cabral (2018), Carmo Jr. e Santos (2010), Carmo Jr. (2012), Lemos, Carmo Jr. e Shimoda (2018) e Ferreira Netto (2017). Na área de Semiótica, os livros de Tatit (2007) e Tatit e Lopes (2008) são bastante conhecidos. Mais recentemente, diversas teses e dissertações têm sido defendidas sobre questões que aproximam as áreas de Música e Linguística, entre as quais podemos citar Raposo de Medeiros (2002), Gelamo (2006), Lima (2007), Souza (2014) e Machado (2017).

$\mathrm{Na}$ área de Fonologia Histórica, trabalhos anteriores desta autora e de sua equipe (MASSINI-CAGLIARI, 2008, 2010, 2011; COSTA, 2010) analisaram cantigas medievais galego-portuguesas profanas e religiosas, mostrando que proeminências musicais combinam-se prioritariamente com proeminências linguísticas, trazendo pistas do acento e do ritmo na oralidade da época. Porém, a análise dos dados comprovou a possibilidade de, em momentos específicos, proeminências musicais serem ocupadas por sílabas que não correspondem a proeminências linguísticas. Entretanto, o encontro entre batidas musicais e linguísticas tem que acontecer na maior parte dos casos, senão a possibilidade de produção e reconhecimento de um padrão rítmico fica prejudicada, já que os padrões de ritmo linguístico, poético e musical baseiam-se na repetição de estruturas.

Em Massini-Cagliari (2019), avançamos na análise da relação entre letra e música, analisando também a linha melódica dos enunciados e verificando se havia alguma relação entre o direcionamento da linha (ascendente, descendente) e a diferença entre afirmação e interrogação, a partir da análise de três Cantigas de Santa Maria, cujas letras contêm tanto frases afirmativas quanto interrogativas. O trabalho apontou que a mesma melodia pode servir para o canto de frases interrogativas e afirmativas; assim, o resultado indicou que parece não haver correlação entre o movimento melódico da música e o do enunciado linguístico.

Embora os estudos da relação entre letra e música tenham se mostrado profícuos para a observação de fenômenos rítmicos, as análises preliminares da melodia sugerem que, para a investigação da entoação de períodos passados da língua, a construção de uma metodologia partindo da relação entre letra e música mostra-se muito mais complexa do que para o ritmo. Começar a enfrentar esta complexidade é um dos objetivos do presente estudo. 


\section{AS CANTIGAS ANALISADAS}

A análise empreendida neste estudo considera as primeiras dez Cantigas de Santa Maria (CSM), uma coleção de 420 cantares, descontadas as repetidas (METTMANN, 1986, p. 7 e 24; PARKINSON, 1998, p. 179), atribuídas a Afonso X, correspondendo ao cancioneiro religioso de louvor à Virgem Maria mais rico da Idade Média.

A escolha por focalizar as dez primeiras CSM vem da estrutura a partir da qual se organiza o cancioneiro religioso, em torno do formato de rosário: as cantigas são organizadas de dez em dez, sendo que as nove primeiras do grupo contam milagres ocorridos por intercessão da Virgem e a décima, identificada por um tipo diferente de rubrica (e por uma miniatura especial, em E), configura um louvor a Santa Maria.

Apesar de as CSM serem atribuídas a Afonso X, sua composição é essencialmente uma atividade coletiva (PARKINSON, 2015, p. 11). Porém, mesmo havendo dúvidas quanto à autoria, de acordo com Leão (2007), indiscutivelmente, Afonso X é o "autor" das CSM, no sentido de que é o chefe da empreitada.

As CSM sobreviveram em quatro códices, aqui referidos a partir das abreviaturas pelas quais são conhecidos: To: Madrid, Biblioteca Nacional, MS 10.069, conhecido como códice de Toledo; T: El Escorial, Real Monasterio de San Lorenzo, MS T.I.1 - códice rico ou códice das histórias; F: Firenze, Biblioteca Nazionale Centrale, Banco Rari, 20 - códice de Florença; e E: El Escorial, Real Monasterio de San Lorenzo, MS B.I.2 - códice dos músicos. O menor e o mais antigo é o códice de Toledo (To); o mais rico em conteúdo artístico é o códice rico de El Escorial (T), que forma um conjunto (os chamados códices das histórias) com o manuscrito de Florença (F), que corresponde ao seu "segundo volume"; e o mais completo é o códice dos músicos - El Escorial (E) (PARKINSON, 1998, p. 180). A época de sua confecção não coincide exatamente, embora sejam todos os quatro manuscritos datados do final do século XIII. To é geralmente considerado um pouco anterior aos demais, enquanto $F$ é considerado um pouco posterior (Anglés, 1943, e Mettmann, 1986, p. 24, são vozes discordantes a este respeito).

A grandiosidade da coleção das CSM se estende ao nível musical, na opinião de Ferreira (1994, p. 58), para quem a coleção é especialmente notável entre a documentação remanescente de música medieval monódica, por duas razões: representa vinte anos de investimento composicional e editorial centralizado; utiliza dois sistemas notacionais semimensurais originais.

De acordo com Fidalgo (2002, p. 204-205), a notação musical da época não tinha a pretensão de reproduzir todos os parâmetros musicais da mesma maneira como a notação musical atual. A maior parte das performances atuais das CSM se baseia na edição de Anglés (1943), que buscava a representação exata da duração e do ritmo dos sons na 
notação das CSM. Por outro lado, Ferreira (1986, p. 188) considera que a interpretação rítmica das CSM deve se pautar na liberdade e na flexibilidade.

Escolhemos a edição de Anglés (1943) para a análise aqui desenvolvida, apesar de haver abordagens divergentes da de Anglés, especialmente Ferreira (1986), Rossell (2006) e Colantuono (2012, 2014), por considerarmos que, apesar das críticas, a edição de Anglés, que é ainda a mais popular em termos de performance musical, pode trazer interessantes dados para a discussão da relação texto-música das CSM.

\section{OBJETIVOS E METODOLOGIA}

Com o objetivo principal de buscar pistas do agrupamento de constituintes prosódicos superiores, tais como a frase entoacional (I) e o enunciado prosódico (U), a partir da consideração da música que acompanha as cantigas religiosas galego-portuguesas, foi traçada uma metodologia, de modo a verificar, a partir da observação da relação entre letra e música, se elementos como duração relativa e proeminência musical trazem pistas do processo de constituência prosódica no nível linguístico, ou seja, da marcação das fronteiras dos constituintes prosódicos superiores e da sua proeminência.

Mettmann (1986, p. 13) mostra que, nas cantigas de milagre, ou seja, nos poemas narrativos (as primeiras nove cantigas de cada decena), o estribilho ou refrão se repete depois de cada estrofe, apresentando a ideia principal, ou a "lição" que se quer passar. Por sua vez, as cantigas não narrativas (louvores) constituem hinos em que Maria é celebrada como auxiliadora, medianeira e procuradora (METTMANN, 1986, p. 14-15). Todas as cantigas são precedidas de epígrafes resumitivas de seu conteúdo. No contexto deste trabalho, as nove primeiras cantigas analisadas são de milagre (CSM19) e a décima (CSM10) é de louvor.

Para exemplificar a estrutura das cantigas de milagre, transcrevemos, em (1), uma das dez CSM aqui consideradas na análise, a CSM3, no seu texto completo, tal como editado por Mettmann (1986, p. 61-62). 
(1)

Esta é como Santa Maria fez cobrar a Theophilo

a carta que fezera cono demo, u se tornou seu vassalo.

\author{
Mais nos faz Santa Maria \\ a seu Fillo perdõar, \\ que nos per nossa folia \\ II' imos falir e errar. \\ Por ela nos perdõou \\ Deus o pecado d'Adam \\ da maçãa que gostou, \\ per que soffreu muit' affan \\ e no inferno entrou; \\ mais a do mui bon talan \\ tant' a seu Fillo rogou, \\ que o foi end' el sacar. \\ Mais nos faz Santa Maria.. \\ Pois ar fez perdon aver \\ a Theophilo, un seu \\ servo, que fora fazer \\ per conssello dun judeu \\ carta por gãar poder \\ cono demo, ella deu; \\ e fez-II' en Deus descreer, \\ des i a ela negar. \\ Mais nos faz Santa Maria..
}

Pois Theophilo assi

fez aquesta trayçon,

\author{
per quant' end' eu aprendi, \\ foy do demo gran sazon; \\ depoys, segund' oý, \\ repentiu-ss' e foy perdon \\ pedir logo, ben aly \\ u peccador sol achar. \\ Mais nos faz Santa Maria... \\ Chorando dos ollos seus \\ muito, foy perdon pedir, \\ u vyu da Madre de Deus \\ a omagen; sen falir \\ lle diss': "Os peccados meus \\ son tan muitos, sen mentir, \\ que, se non per rogos teus, \\ non poss' eu perdon gãar.» \\ Mais nos faz Santa Maria... \\ Theophilo dessa vez \\ chorou tant' e non fez al, \\ trões u a que de prez \\ todas outras donas val, \\ ao demo mais ca pez \\ negro do fog' infernal \\ a carta trager-lle fez, \\ e deu-lla ant' o altar. \\ Mais nos faz Santa Maria...
}

A terceira cantiga do cancioneiro religioso sobreviveu em três dos quatro códices que registram as CSM. De modo a mostrar que os códices registram a melodia apenas para a primeira estrofe e para o refrão, reproduzimos, nas figuras 1,2 e 3, o registro dessa cantiga nos códices de Toledo (To), Escorial rico (T) e Escorial (E). Esse fato dá suporte à razão pela qual, metodologicamente, escolheu-se, aqui, analisar apenas a primeira estrofe e o refrão das dez cantigas escolhidas, uma vez que, com relação a eles, existe a certeza de como se dava a relação entre letra e música. 

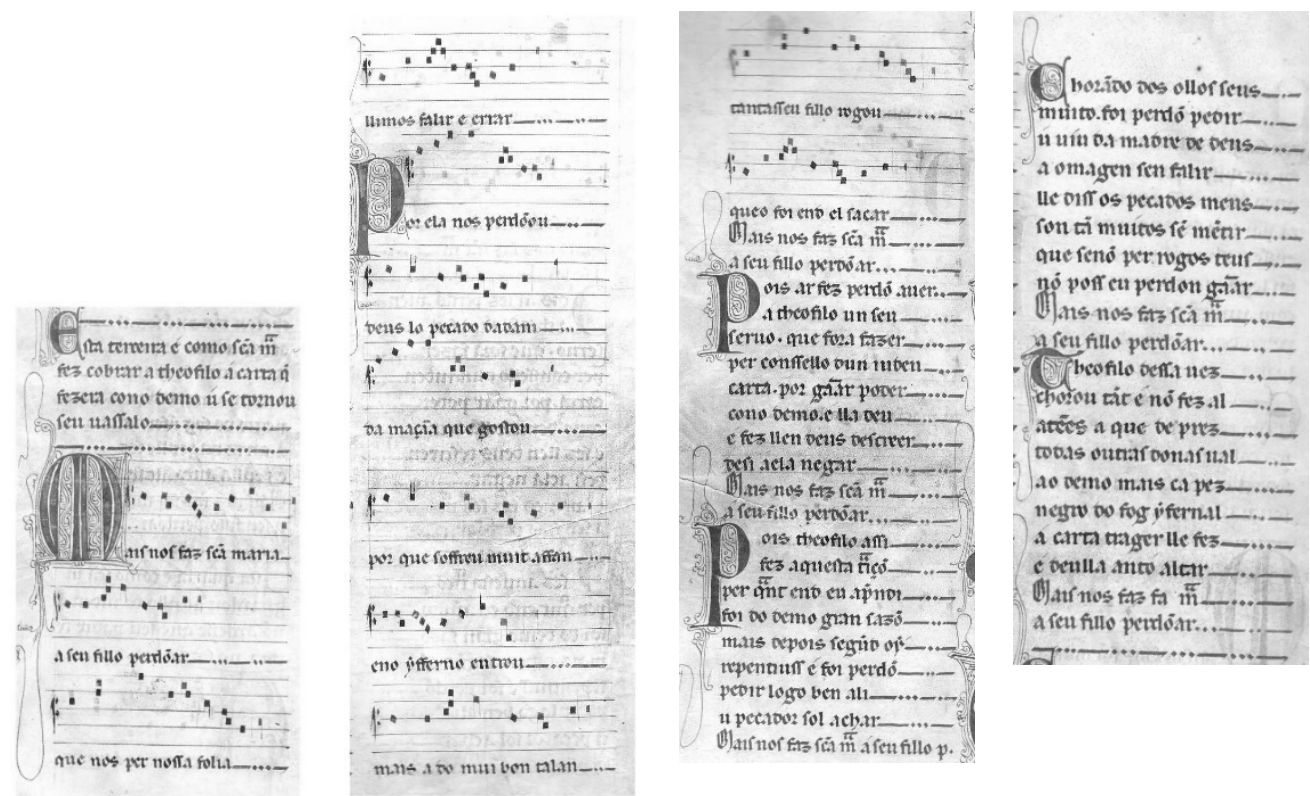

Figura 1. Tolll (CSM3). Fonte: Cantigas de Santa María. Edición facsímile do Códice de Toledo(To). Biblioteca Nacional de Madrid (Ms. 10.069). Vigo: Consello da Cultura Galega, Galáxia, 2003. fólios 11r-11v.

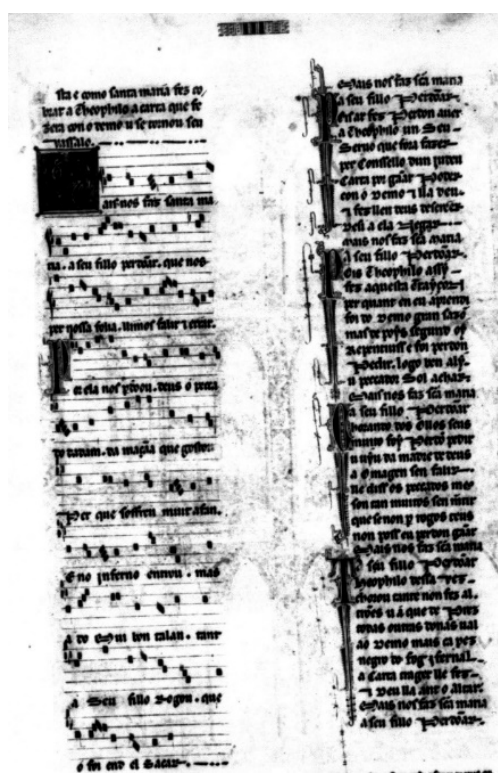

Figura 2. T3 (CSM3). Fonte: Códice Escorial rico (microfilme cedido pela Biblioteca Real Monasterio de San Lorenzo, El Escorial, MS T.I.1). fólio 7v. 

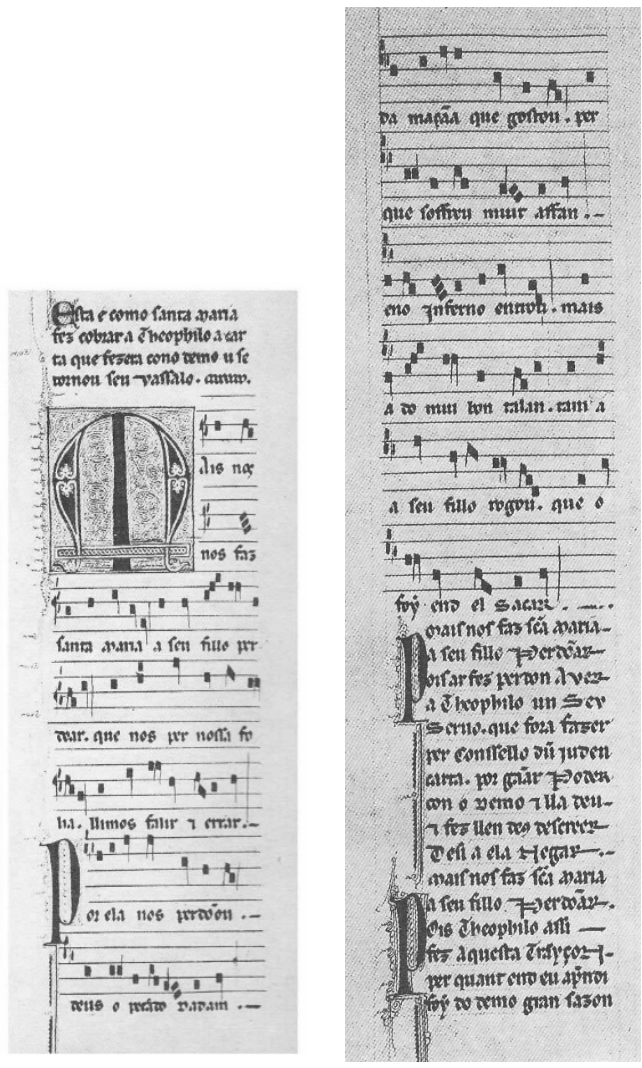

mur torpis forsum of

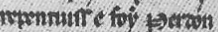

Hoth. Logo ben atf

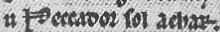

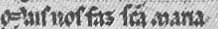

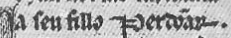

horanw wo suos ime

munक for arton $x$ dir

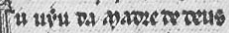

a 0 nusger fon falre.

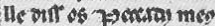

for can mutros fen mín

atue fe non 2 1)

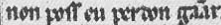

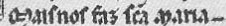

3.

(4hovinle sim - Ves

chosou ratit enen frsat.

trits 4 a nuc $\pi \mathrm{r}^{2} \mathrm{~m}$

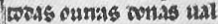

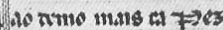

กัg

A can matritle for

7 malla atte o. llaz2.

marnorfas ich numa

a fer fillo $7 \Rightarrow$ rroarar.

g̈nos per noth folls -

Umios faltrา enar-

Figura 3. E3 (Cantiga CSM3). Códice dos músicos (Escorial), fólios 30v-31r. (Reproduzido de Anglés, 1964, 30v-31r).

Também a edição de Anglés (1943), utilizada para a análise aqui desenvolvida, distribui apenas os versos do refrão e da primeira estrofe sob a notação musical resultante da edição, que faz a transposição dos dois tipos de notação musical medieval utilizados nos códices para uma notação atualizada, que possa ser lida por usuários contemporâneos, inclusive visando a performances. A opção por sustentar a análise em uma edição da música das CSM vem da necessidade de conhecimentos técnicos especializados para a interpretação da notação musical medieval, que apenas musicólogos dedicados à pesquisa e à edição desses manuscritos têm. Assim sendo, o respeito pelo trabalho realizado anteriormente por esses grandes estudiosos da música medieval abre espaço para que, alicerçados no conhecimento anterior já construído, possamos avançar nas pesquisas ainda por fazer, como, por exemplo, a que se pretende aqui, a respeito da prosódia linguística do ancestral medieval da nossa língua. Na figura 4, transcrevemos a edição de Anglés (1943, p. 7-8) para a CSM3. 
Esta é coino Santa Maria fez cobrar a Theophilo a carta que fezera con o demo, u se tornou seu oussalo.

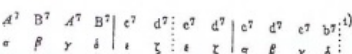
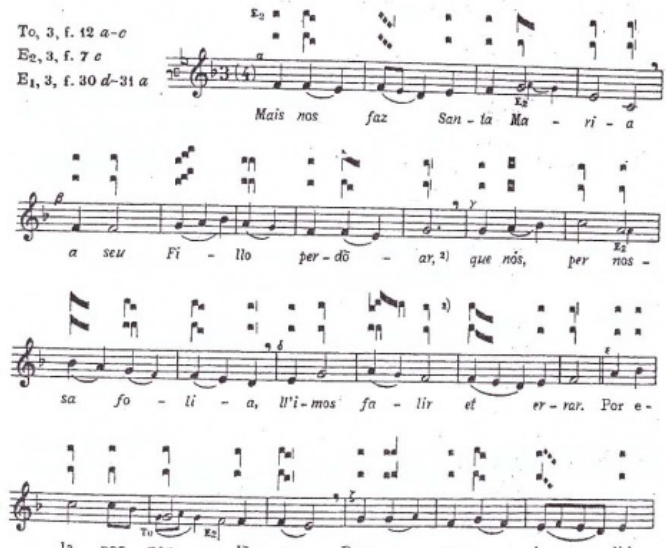

la nos per - do-ou, Deus o pecca - do d'A
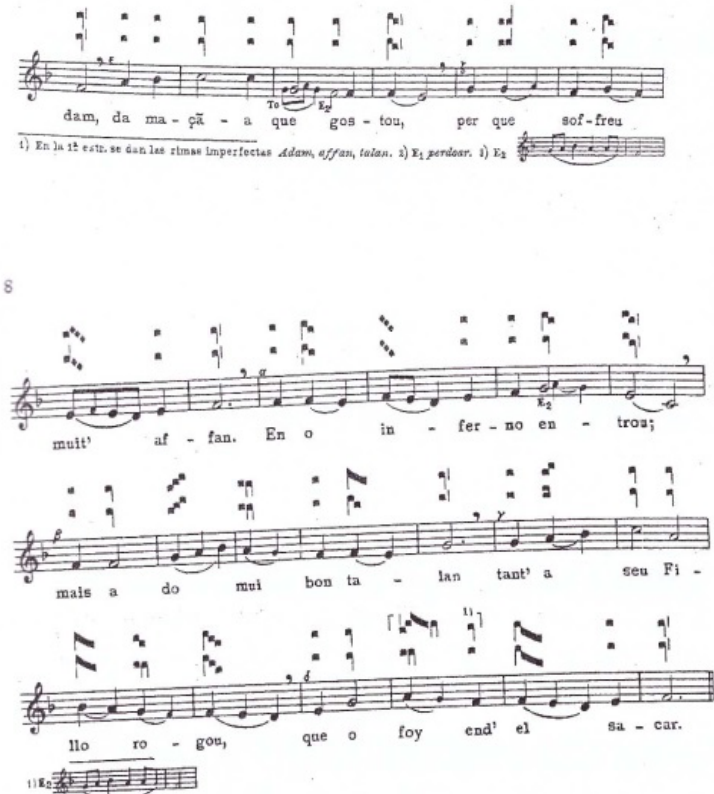

Figura 4. CSM20: notação musical. Fonte: Adaptado de Anglés (1943, p. 28)

Colantuono (2012, p. 56) aponta que, na música da CSM, pode haver "percursos melódicos independentes do desenvolvimento do texto literário", porque a melodia da primeira estrofe se impõe aos demais versos. Por isso, em relação aos demais versos das cantigas, a melodia teria autonomia em relação ao texto, sendo o veículo de sua memorização e transmissão. Esta observação reforça ainda mais a opção por focalizar, 
neste trabalho, apenas a primeira estrofe de cada cantiga e o refrão, sobre os quais as relações entre prosódia musical e prosódia linguística foram construídas.

A análise parte, primeiramente, da segmentação dos versos da primeira estrofe e do refrão das cantigas consideradas em constituintes prosódicos (SELKIRK, 1980, 1984; NESPOR; VOGEL, 1986; VIGÁRIO, 2001; TENANI, 2002; BISOL, 2005). Segundo Vigário (2001, p. 2), as vantagens do modelo prosódico são duas: trazer para dentro do componente fonológico todas as manifestações prosódicas, não somente a acentuação, o ritmo e a silabação, incluindo a entoação; e admitir certa flexibilidade na construção dos constituintes prosódicos, permitindo que um mesmo enunciado possa ser dividido diferentemente, o que geraria diferentes nuances de significado. Em (2), apresentamos os constituintes prosódicos, a partir da teoria de domínios de Nespor e Vogel (1986), na leitura de Bisol (2005, p. 244):

(2)

\begin{tabular}{ll}
\hline Hierarquia prosódica & \\
\hline enunciado & $U$ (do inglês, utterance) \\
frase entoacional & $\mathrm{I}($ do inglês, intonational phrase $)$ \\
frase fonológica & $\phi$ \\
grupo clítico & $\mathrm{C}$ \\
palavra fonológica & $\omega$ \\
pé & $\Sigma$ \\
sílaba & $\sigma$ \\
\hline
\end{tabular}

É importante esclarecer que nem todos os trabalhos da área consideram a existência do grupo clítico (C) enquanto constituinte prosódico. Com relação a esta questão, especificamente para o PA, consideraremos sua existência, posicionando-o na hierarquia dos constituintes prosódicos, a partir dos resultados obtidos por Amaral (2013), que estudou o direcionamento da adjunção de clíticos fonológicos no PA a partir de cantigas medievais galego-portuguesas religiosas e profanas. A tese de Amaral (2013) traz argumentos a favor de se considerar a existência de um constituinte intermediário como um nível hierárquico importante dentro da estrutura prosódica do PA, entre palavra fonológica e a frase fonológica, a partir da análise de três tipos de pistas: as que vêm do fenômeno de interpolação sintática, as que vêm da consideração de estruturas prosódicas inseparáveis e as que vêm do processo de elisão.

Para a segmentação, consideramos, como Verluyten (1982), para os textos poéticos, uma equivalência entre enunciado prosódico e verso. No caso de versos longos, em que ocorre cesura, consideram-se dois enunciados fonológicos por verso. Verluyten (1982, p. 257) propôs uma correspondência entre categorias métricas (isto é, poéticas) e categorias prosódicas (ou seja, linguísticas). Embora cada categoria métrica tenha sua correspondente linguística, elas não necessariamente coincidem; em outras palavras, embora a estrutura linguística seja a base da produção dos versos, as categorias métricas 
e prosódicas não são co-extensivas - caso contrário, a distinção entre métrica poética e prosódia linguística não faria sentido.

Apresentamos, adiante, a título de ilustração, como foi feita a identificação da proeminência dos constituintes I e $U$, em cada verso, para, posteriormente, possibilitar a análise da duração da(s) nota(s) musical(is) que coincide(m) com a sílaba que carrega a proeminência da frase entoacional (I). Como mostram os exemplos (3-5), a segmentação em constituintes prosódicos foi realizada de maneira bottom-up, seguindo os preceitos de constituição prosódica colocados principalmente por Nespor e Vogel (1986). Em relação à constituição das sílabas do PA, partiu-se da segmentação do verso em sílabas poéticas, equivalentes a sílabas fonéticas, atestadas pela métrica de cada verso, que, por sua vez, é alicerçada na isometria com relação à extensão dos versos, quando comparadas as estrofes. Essa segmentação também levou em consideração os resultados dos trabalhos anteriores de Zucarelli (2002), Biagioni (2002), Cangemi (2014) e Massini-Cagliari (2015), sobre a silabação do PA. Por sua vez, a determinação da extensão e das relações de proeminências em nível do pé $(\Sigma)$ seguem Massini-Cagliari $(1999,2015)$, para quem o ritmo do PA, em termos fonológicos, se baseia na construção de pés troqueus moraicos. Trata-se, pois, de considerar uma alternância binária, com proeminência inicial, porém sensível ao peso das sílabas, uma vez que sílabas pesadas em posição final de palavra atraem o acento. ${ }^{1}$

O primeiro exemplo, transcrito em (3), corresponde ao verso 10 da CSM7 (aqui transcrito na versão de Mettmann, 1986, p. 76). Mostra a coincidência da proeminência de I com a proeminência do enunciado, ou seja, o enunciado prosódico, equivalente ao verso, é realizado a partir de uma única frase entoacional.

(3)

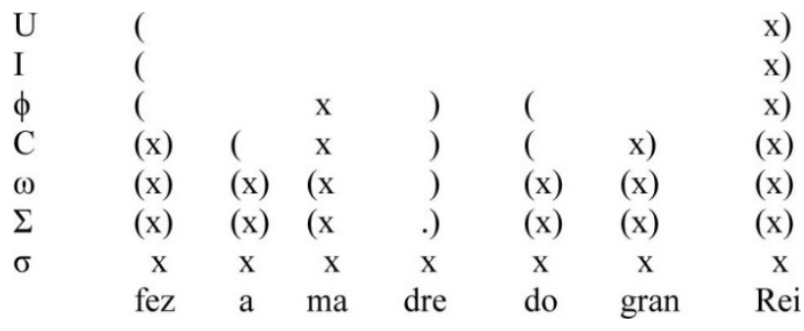

Já o primeiro verso da CSM10, transcrito em (4), a partir da leitura de Mettmann (1986, p. 84), mostra um verso, equivalente ao enunciado fonológico, realizado por duas frases entoacionais (I), congregadas em um único enunciado prosódico (U). 
(4)

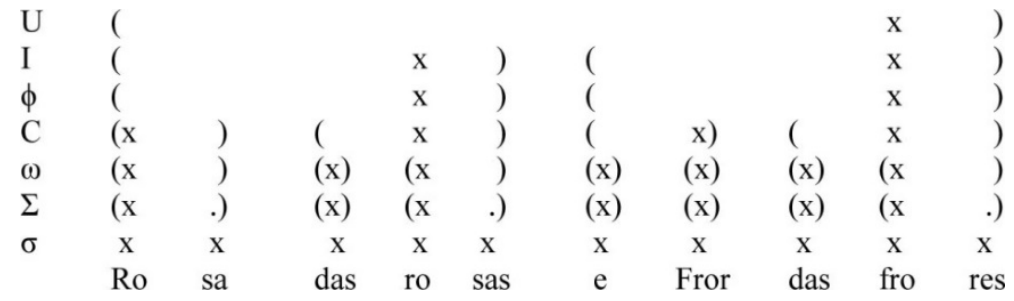

Por sua vez, o exemplo transcrito em (5), que corresponde ao verso 7 da CSM 8, a partir de Mettmann (1986, p. 78), mostra um verso dividido por uma cesura (= pausa poética). Neste caso, cada metade do verso é considerada como um enunciado prosódico (U), com sua respectiva proeminência.

(5)

\begin{tabular}{|c|c|c|c|c|c|c|c|c|c|c|c|c|c|c|}
\hline $\mathrm{U}$ & & & & & & $x$ & ) & ( & & & & & & $\mathrm{x})$ \\
\hline ( & & & & & & $x$ & ) & ( & & & & & & $\mathrm{x})$ \\
\hline ( & & $x$ & ) & ( & & $x$ & ) & ( & x) & ( & & & & $\mathrm{x})$ \\
\hline C & & $\mathrm{x}$ & ) & (x) & ( & $\mathrm{x}$ & ) & (x) & (x) & ( & & & & $\mathrm{x})$ \\
\hline ( & & $x$ & ) & (x) & ( & $x$ & ) & (x) & (x) & (x) & ( & & & $\mathrm{x})$ \\
\hline (x & .) & (x & .) & (x) & (x) & (x & .) & (x) & (x) & (x) & (x) & (x & .) & (x) \\
\hline $\mathrm{x}$ & $\mathrm{x}$ & $\mathrm{x}$ & $x$ & $\mathrm{x}$ & $\mathrm{x}$ & $\mathrm{x}$ & $x$ & $\mathrm{x}$ & $x$ & $\mathrm{x}$ & $x$ & $\mathrm{x}$ & $x$ & $x$ \\
\hline $\mathrm{a}$ & ve & re & des & poy & l'o & ir & des & que & fez & en & Ro & ca & $\mathrm{ma}$ & dor \\
\hline
\end{tabular}

Identificadas as proeminências dos constituintes I e U, em cada verso, a próxima etapa foi a análise da duração da(s) nota(s) musical(is) que coincide(m) com a sílaba que carrega a proeminência da frase entoacional (I). A figura 5 traz a edição do verso 10 da CSM7, anteriormente transcrito e analisado quanto aos constituintes prosódicos em (3), na edição de Anglés (1943, p. 14). A figura ilustra o procedimento de análise da duração da(s) nota(s) musical(is) que coincide $(m)$ com a proeminência linguística de $I$, verificando se, com relação às notas circundantes, sua duração é relativamente maior, menor ou igual. A(s) nota(s) com a(s) qual(is) a duração da(s) nota(s) musical(is) que coincide(m) com a proeminência linguística de I está(ão) sendo comparada(s) é assinalada com uma seta curva. No caso ilustrado na figura 5, a nota que coincide com a palavra Rei, monossilábica e tônica, é relativamente mais longa do que a nota correspondente à palavra gran, que a precede.

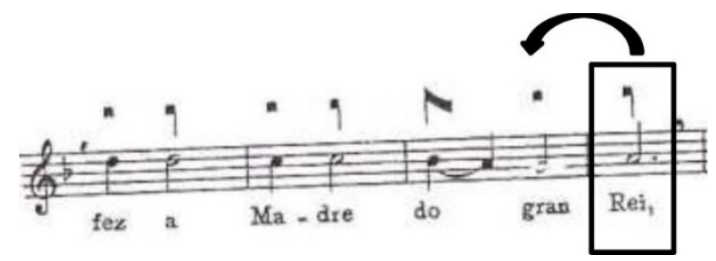

Figura 5. CSM7: notação musical: linha 7. Fonte: Anglés (1943, p. 14)

Já a figura 6 traz o primeiro verso da CSM10 (ANGLÉS, 1943, p. 18), analisado com relação aos constituintes prosódicos em (4), em que os versos, equivalentes a $U$, se 
estruturam a partir de dois I, cada um com uma proeminência. Por ser cada um dos Is finalizado por palavra paroxítona, a proeminência principal de I não corresponde à última sílaba de I. Na figura 6, a sílaba tônica da palavra rosas, ro, corresponde à proeminência do primeiro I, sendo que a duração das notas das duas sílabas da palavra rosas é equivalente, porém a duração da nota correspondente à sílaba anterior, das, é menor. Com relação à sílaba inicial de frores, fro, que corresponde à proeminência principal do segundo I, a duração da sílaba átona final, res, é maior do que a da sílaba inicial, fro. A duração da nota correspondente à sílaba das, que a precede, é também maior.

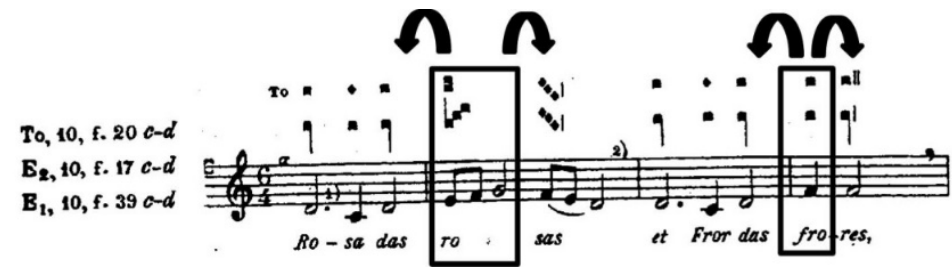

Figura 6. CSM10: notação musical: linha 1. Fonte: Anglés (1943, p. 18).

Foi observada, também, em um segundo momento, a duração da última sílaba do verso, que corresponde ao limite final de $\mathrm{U}$, para verificar se a(s) nota(s) musical(is) que coincide(m) com a sílaba final de $U$ apresenta(m) algum diferencial específico, em termos de duração. Para ilustrar o procedimento metodológico, trazemos a figura 7 , em que as sílabas finais dos dois enunciados fonológicos $(U)$ que compõem o verso foram analisadas. Na primeira metade antes da cesura, a sílaba correspondente ao limite final de $U$ é a sílaba final do verbo oirdes, des, átona; na segunda metade, a sílaba final de U é tônica, correspondendo à última sílaba da palavra Rocamador, dor. Em ambos os casos, independentemente da diferença de tonicidade entre as sílabas, observa-se que a nota que corresponde à sílaba final de $U$ apresenta uma maior duração, em comparação com as sílabas que a precedem.

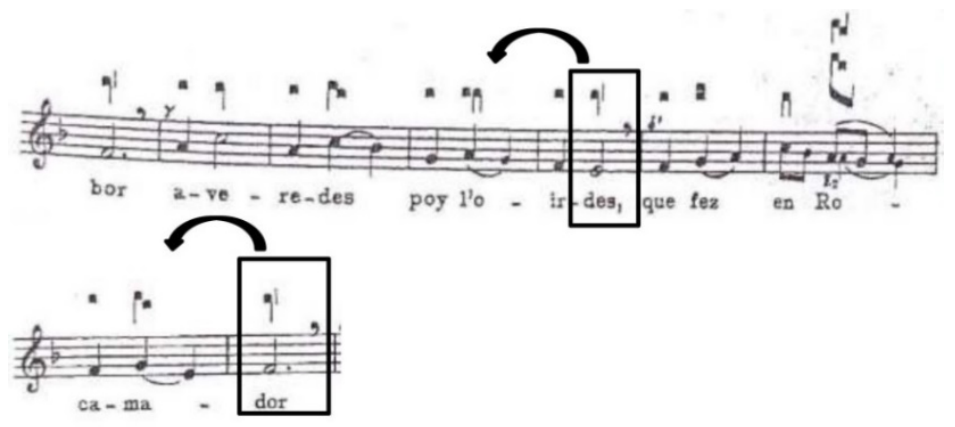

Figura 7. CSM8: notação musical: linhas 5 e 6. Fonte: Anglés (1943, p. 15-16). 


\section{ANÁLISE DOS DADOS: EM BUSCA DE PISTAS DA CONSTITUÊNCIA PROSÓDICA DO PA}

Seguindo os procedimentos metodológicos explicitados na seção anterior deste artigo, procedemos à análise da duração da(s) nota(s) musical(is) que coincide(m) com a sílaba que carrega a proeminência da frase entoacional (I), em todos os versos dos refrões e das primeiras estrofes das dez primeiras CSM. Com base na comparação da duração da sílaba em posição de proeminência de I com a duração das notas musicais correspondentes às sílabas circundantes (anterior e posterior, quando houver) à sílaba que carrega a proeminência de I, foi construída a tabela 1, que traz os dados divididos pelas dez cantigas, mostrando que, em $76.8 \%$ dos casos, a duração da(s) nota(s) musical(is) que coincide(m) com a sílaba que carrega a proeminência da frase entoacional (I) tem duração maior do que a das sílabas circundantes, o que talvez evidencie uma tendência à marcação da proeminência de I a partir da duração mais longa da sílaba proeminente.

\begin{tabular}{|c|c|c|c|c|}
\hline $\begin{array}{c}\text { Cantiga de Santa } \\
\text { Maria }\end{array}$ & Duração maior & Duração igual & Duração menor & Subtotal \\
\hline 1 & 14 & 6 & 0 & 20 \\
\hline 2 & 23 & 0 & 3 & 26 \\
\hline 3 & 20 & 1 & 3 & 24 \\
\hline 4 & 16 & 0 & 8 & 24 \\
\hline 5 & 15 & 0 & 7 & 12 \\
\hline 6 & 8 & 4 & 0 & 18 \\
\hline 7 & 18 & 0 & 0 & 12 \\
\hline 8 & 6 & 0 & 0 & 20 \\
\hline 9 & 20 & 0 & 6 & 12 \\
\hline 10 & 6 & 0 & $33(17.4 \%)$ & $190(100 \%)$ \\
\hline
\end{tabular}

Tabela 1. Comparação da duração da sílaba em posição de proeminência de I com a duração das notas musicais correspondentes às sílabas circundantes (anterior e posterior, quando houver) à sílaba que carrega a proeminência de l.

Refinando a análise apresentada na tabela 1, relacionamos, na tabela 2, a duração da(s) nota(s) musical(is) que coincide(m) com a sílaba que carrega a proeminência da frase entoacional (I) à posição da proeminência rítmica musical, ou seja, ao fato de essa sílaba específica ocupar a posição inicial, forte, do compasso musical. A tabela 2 mostra que, analisando a correlação entre esses dois fatores, pode ser identificada uma tendência a fazer coincidir, sobre a sílaba que carrega a proeminência de I, uma maior duração e a proeminência rítmica musical, fatores ambos que promovem a saliência prosódica, em nível musical. Em se considerando a possibilidade, na poesia cantada, de a prosódia musical, em termos de proeminência, se alicerçar prioritariamente sobre as proeminências linguísticas (MASSINI-CAGLIARI, 2008), é possível considerar essa coincidência como pista da constituição prosódica e dos limites de I. Em se considerando também as sílabas em posição de proeminência de I que apresentam duração menor ou igual na(s) nota(s) musical(is) que as acompanha(m), percebe-se que em $83.1 \%$ dos casos, a sílaba 
proeminente de I ocorre na posição de proeminência rítmica musical. Esse percentual indica que parece haver uma preferência pela cumulação na marcação de I por ambos, duração e proeminência (=acento) musical, na marcação da proeminência entoacional no estabelecimento da relação entre prosódia linguística e prosódia musical na combinação da letra e da música da canção. Por outro lado, a co-ocorrência com a proeminência rítmica na marcação da proeminência de l e, consequentemente, na constituição e no estabelecimento dos limites de I, apresenta um percentual ligeiramente mais alto do que o de o verificado para a coincidência da proeminência linguística de I com a ocorrência de maior duração no nível musical. Este resultado pode indicar, como aliás já mostrava Halliday (1970), que entoação e ritmo não devem ser analisados independentemente, uma vez que as proeminências nesses níveis se inter-relacionam.

\begin{tabular}{|c|c|c|c|c|c|c|c|}
\hline \multirow{2}{*}{$\begin{array}{l}\text { Cantiga } \\
\text { de } \\
\text { Santa } \\
\text { Maria }\end{array}$} & \multicolumn{2}{|c|}{ Duração maior } & \multicolumn{2}{|c|}{ Duração igual } & \multicolumn{2}{|c|}{ Duração menor } & \multirow[t]{2}{*}{ Subtotal } \\
\hline & $\begin{array}{l}\text { Com proe- } \\
\text { minência } \\
\text { musical }\end{array}$ & $\begin{array}{l}\text { Sem proe- } \\
\text { minência } \\
\text { musical }\end{array}$ & $\begin{array}{l}\text { Com proe- } \\
\text { minência } \\
\text { musical }\end{array}$ & $\begin{array}{l}\text { Sem proe- } \\
\text { minência } \\
\text { musical }\end{array}$ & $\begin{array}{l}\text { Com proe- } \\
\text { minência } \\
\text { musical }\end{array}$ & $\begin{array}{l}\text { Sem proe- } \\
\text { minência } \\
\text { musical }\end{array}$ & \\
\hline 1 & 14 & 0 & 3 & 3 & 0 & 0 & 20 \\
\hline 2 & 17 & 6 & 0 & 0 & 1 & 2 & 26 \\
\hline 3 & 16 & 4 & 0 & 1 & 1 & 2 & 24 \\
\hline 4 & 12 & 4 & 0 & 0 & 8 & 0 & 24 \\
\hline 5 & 15 & 0 & 0 & 0 & 0 & 7 & 22 \\
\hline 6 & 8 & 0 & 4 & 0 & 0 & 0 & 12 \\
\hline 7 & 18 & 0 & 0 & 0 & 0 & 0 & 18 \\
\hline 8 & 6 & 0 & 0 & 0 & 6 & 0 & 12 \\
\hline 9 & 20 & 0 & 0 & 0 & 0 & 0 & 20 \\
\hline 10 & 6 & 0 & 0 & 0 & 3 & 3 & 12 \\
\hline & 132 (69.4\%) & $14(7.4 \%)$ & $7(3.7 \%)$ & $4(2.1 \%)$ & 19 (10\%) & $14(7.4 \%)$ & 190 (100\%) \\
\hline
\end{tabular}

Tabela 2. Relação entre a duração da(s) nota(s) musical(is) que coincide(m) com a sílaba que carrega a proeminência de l e a posição da proeminência rítmica musical.

Por último, averiguando a possibilidade de identificação de alguma pista da constituição e dos limites do constituinte prosódico superior, ou seja, o enunciado prosódico (U), foi feita uma análise da relação entre a duração da(s) nota(s) musical(is) que coincide(m) com a sílaba que carrega a proeminência do enunciado prosódico $(U)$ e a pauta prosódica da sílaba (tônica ou átona) na posição final de U, apresentada na tabela 3. Essa tabela analisa a duração da sílaba em limite final de $U$, quer esta seja tônica (no caso de $U$ ser finalizado por uma palavra oxítona), quer seja átona (no caso de finalização de $U$ por uma palavra paroxítona). ${ }^{2} \mathrm{~A}$ quantificação dos dados mostrou que a sílaba final de $\mathrm{U}$ apresenta maior duração relativa, comparativamente às sílabas que a precedem, em $85.4 \%$, o que pode apontar para a duração como uma marca importante do limite final de U. 


\begin{tabular}{|l|r|r|r|r|r|}
\hline Cantiga de & \multicolumn{2}{|l|}{ Duração maior } & \multicolumn{2}{l|}{ Duração menor ou igual } & \multicolumn{1}{l}{ Subtotal } \\
\cline { 2 - 7 } Santa Maria & tônica & & tônica & \multicolumn{1}{c|}{ átona } & \\
\hline 1 & 4 & 6 & 0 & 0 & 10 \\
\hline 2 & 0 & 0 & 0 & 13 & 13 \\
\hline 3 & 10 & 1 & 0 & 0 & 12 \\
\hline 4 & 9 & 3 & 0 & 0 & 12 \\
\hline 5 & 8 & 0 & 0 & 4 & 12 \\
\hline 6 & 2 & 6 & 0 & 0 & 18 \\
\hline 7 & 12 & 6 & 0 & 0 & 12 \\
\hline 8 & 3 & 9 & 0 & 0 & 20 \\
\hline 9 & 0 & 20 & 0 & 0 & 6 \\
\hline 10 & 3 & 3 & 0 & $18(14.6 \%)$ & $123(100 \%)$ \\
\hline
\end{tabular}

Tabela 3. Relação entre a duração da(s) nota(s) musical(is) que coincide(m) com a sílaba que carrega a proeminência do enunciado prosódico (U) e a pauta prosódica da sílaba (tônica ou átona) na posição final de $U$.

\section{CONCLUSÃO}

Objetivando buscar pistas do agrupamento de constituintes prosódicos superiores, tais como a frase entoacional (I) e o enunciado prosódico (U), a partir da consideração da música que acompanha as cantigas religiosas galego-portuguesas, este estudo partiu da construção de uma metodologia, de modo a verificar, por meio da observação da relação entre letra e música, se fatores como duração e proeminência musical podem elucidar o processo de constituência prosódica no nível linguístico, ou seja, a marcação das fronteiras dos constituintes prosódicos superiores e a sua proeminência.

A análise da duração da(s) nota(s) musical(is) que coincide(m) com a sílaba que carrega a proeminência da frase entoacional (I) revelou que, na maioria dos casos, a sílaba que carrega a proeminência da frase entoacional (I) tem duração maior do que a das sílabas circundantes, o que pode evidenciar uma tendência à marcação da proeminência de l a partir da duração mais longa da sílaba proeminente.

Relacionando a duração da(s) nota(s) musical(is) que coincide(m) com a sílaba que carrega a proeminência da frase entoacional (I) com a posição da proeminência rítmica musical, verificou-se que, na maioria expressiva dos casos (83.1\%), a sílaba proeminente de I ocorre na posição de proeminência rítmica musical, o que pode indicar uma preferência pela cumulação de fatores rítmicos e melódicos na marcação da saliência de I.

Por outro lado, com relação ao enunciado prosódico, o alongamento da duração, em nível musical, no final do constituinte, apresenta-se quase categórico, atingindo tanto sílabas tônicas quanto átonas, revelando-se um indício confiável para a segmentação de $\mathrm{U}$.

Neste sentido, na ausência de registros orais da época, consideramos que o estudo desenvolvido possibilita alcançar pistas, mesmo que indiciais, de como teria se constituído a prosódia da época, no sentido de como se relacionavam ritmo e melodia, tanto em termos musicais quanto linguísticos. Desta forma, o antes "inaudível" torna-se um "murmúrio", mesmo que baixinho. Esperamos que, com o possível desenvolvimento futuro da 
metodologia aqui proposta, o volume do som dos trovadores medievais, nossos ancestrais linguísticos, possa ser aumentado, tornando-se a sua prosódia mais "audível”.

\section{AGRADECIMENTOS}

Esta pesquisa foi desenvolvida com o suporte do CNPq (Processo 302648/2019-4), a quem agradecemos.

\section{REFERÊNCIAS}

AFONSO X O SABIO. Cantigas de Santa María. edición facsímile do Códice de Toledo (To). Biblioteca Nacional de Madrid (Ms. 10.069). Vigo: Consello da Cultura Galega, Galáxia, 2003.

AMARAL, T. T. A prosodização de pronomes oblíquos no Português Arcaico. Araraquara: FCL/UNESP. Tese de Doutorado (Linguística e Língua Portuguesa), 2017.

ANGLÉS, H. La Música de las Cantigas de Santa María del Rey Alfonso el Sabio. Facsímil, transcripción y estudio critico por Higinio Anglés. Barcelona: Diputación Provincial de Barcelona; Biblioteca Central; Publicaciones de la Sección de Música, 1943. Volume II - Transcripción Musical.

ANGLÉS, H. La música de las Cantigas de Santa María del Rey Alfonso el sabio: facsímil, transcripción y estudio critico por Higinio Anglés. Barcelona: Diputación Provincial de Barcelona; Biblioteca Central; Publicaciones de la Sección de Música, 1964.

BIAGIONI, A. B. A Silaba em Português Arcaico. Araraquara: FCL/UNESP. Dissertação de Mestrado (Linguística e Língua Portuguesa), 2002.

BISOL, L. Constituintes prosódicos. In: BISOL, L. (Org.). Introdução a estudos de fonologia do português brasileiro. $4^{2}$ edição revista e ampliada. Porto Alegre: EDIPUCRS, 2005. p. 243-255. [1ª edição: 1996.]

CANGEMI, A. C. F. G. A. Sândi vocálico externo no Português Arcaico. Araraquara: FCL/UNESP. Tese de Doutorado (Linguística e Língua Portuguesa), 2014.

CARMO JR., J. R. Sobre a gramática da palavra cantada. Caderno de Estudos Linguísticos. (54.2), Campinas, Jul./Dez. 2012.

CARMO JR., J. R.; SANTOS, R. S. Hierarquia prosódica e hierarquia melódica na canção Gabriela. D.E.L.T.A. São Paulo, 26:2, 2010, 319-343.

COLANTUONO, M. I. Cantigas de Santa Maria di Alfonso X el Sabio: Composizione musicale e oralità. Tese Doutoral. Barcelona: Universitat Autònoma de Barcelona, 2012. https://www.tdx.cat/handle/10803/96668\#page=1

COLANTUONO, M. I. Reminiscenze melodiche e filiazioni tematiche tra le Cantigas de Santa Maria e le Prosae de Santa Maria del Codice di Las Huelgas. Cognitive Philology 7 (2014): 1-29.

COSTA, D. S. A interface música e lingüística como instrumental metodológico para o estudo da prosódia do português arcaico. Araraquara: FCL/UNESP. Tese de Doutorado (Linguística e Língua Portuguesa), 2010.

FERREIRA, M. P. O som de Martin Codax. sobre a dimensão musical da lírica galego-portuguesa (séculos XII-XIV). Lisboa: UNYSIS, Imprensa Nacional - Casa da Moeda, 1986.

FERREIRA, M. P. The Stemma of the Marian Cantigas: Philological and Musical Evidence. Bulletin of the Cantigueiros de Santa Maria, Cincinnati, n. 6, p. 58-98, 1994. 
FERREIRA NETTO, W. Fonologia, discurso e interdisciplinaridade. Relações possíveis entre a fonologia e a músicas. In: SEMINÁRIO INTERNACIONAL DE LINGUÍSTICA, 7; CONGRESSO INTERDISCIPLINAR DE CORTESIA, 3; SIMPÓSIO DE LINGUÍSTICA TEXTUAL, 2. Universidade Cruzeiro do Sul, São Paulo, 15/07/2017. DOI: 10.13140/RG.2.2.31642.54722.

FIDALGO, E. As Cantigas de Santa María. Vigo: Xerais, 2002.

FONTE, J. S. Rumores da escrita, vestígios do passado: Uma interpretação fonológica das vogais do português arcaico por meio da poesia medieval. São Paulo: Cultura Acadêmica, 2010.

FONTE, J. S. As Vogais na Diacronia do Português: uma interpretação fonológica de três momentos da história da língua. Araraquara: FCL/UNESP. Tese de Doutorado (Linguística e Língua Portuguesa), 2014.

GELAMO, R. P. Organização prosódica e interpretação de canções: a frase entoacional em quatro diferentes interpretações de Na Batucada da Vida. Dissertação (Mestrado em Linguística). IBILCE, Unesp, São José do Rio Preto, 2006.

GEMENTI, M. M. Consoantes fricativas: um estudo das relações entre letras e sons na lírica medieval galegoportuguesa. Araraquara: FCL/UNESP. Tese de Doutorado (Linguística e Língua Portuguesa), 2018.

HALLIDAY, M.A.K. A Course in Spoken English: Intonation. Oxford: Oxford University Press, 1970.

JACKENDOFF, R.; LERDAHL, F. A Deep Paralle/ Between Music and Language. Bloomington: Indiana University Linguistics Club, 1980

LEÃO, A. V. Cantigas de Santa Maria de Afonso X, o sábio. Aspectos culturais e literários. São Paulo: Linear B; Belo Horizonte: Veredas \& Cenários, 2007.

LEMOS, C. L.; CARMO JR., J. R.; SHIMODA, L. T. A interação entre expressões na canção: repetições e hierarquia. In: LOPES, I. C.; SOUZA, P. M. (Orgs.) Estudos semióticos do plano da expressão. São Paulo: FFLCH/USP, 2018, p. 222241.

LERDAHL, E.; JACKENDOFF, R. A generative theory of tonal music. Cambridge: The MIT Press, 1983.

LIMA, J. G. Ritmo e Melodia no Poema Lido e Musicalizado: Alguns exemplos do repertório brasileiro. Dissertação (Mestrado em Estudos Literários). Universidade Federal do Paraná, Curitiba, 2007.

MACHADO, A. L. Diferenças na percepção de emoções em enunciados verbais declamados e cantados. Dissertação (Mestrado em Linguística e Língua Portuguesa). FCL, Unesp, Araraquara, 2017.

MASSINI-CAGLIARI, G. Cantigas de amigo: do ritmo poético ao lingüístico. Um estudo do percurso histórico do acentuação em Português. Tese (Doutorado em Linguística). IEL, Unicamp, Campinas, 1995.

MASSINI-CAGLIARI, G. Do poético ao lingüistico no ritmo dos trovadores: três momentos da história do acento. Araraquara: FCL, Laboratório Editorial, UNESP; São Paulo: Cultura Acadêmica, 1999.

MASSINI-CAGLIARI, G. Das cadências musicais para o ritmo lingüístico: Uma análise do ritmo do Português Arcaico, a partir da notação musical das Cantigas de Santa Maria. Revista da ABRALIN, v. 7, n. 1, p. 9-26, jan./jun. 2008.

MASSINI-CAGLIARI, G. From Musical Cadences to Linguistic Prosody: How to Abstract Speech Rhythm of the Past. In: PARTRIDGE, John (ed.) Interfaces in language. Newcastle upon Tyne: Cambridge Scholars, 2010. p. 113-134.

MASSINI-CAGLIARI, G. Contribuição para a análise do ritmo linguístico das cantigas medievais profanas e religiosas a partir de uma interface Música-Linguística. In: REBELO, Helena (Coord.) Lusofonia: Tempo de Reciprocidades. Actas do IX Congresso da Associação Internacional de Lusitanistas. Madeira, 4 a 9 de agosto de 2008. Porto: Edições Afrontamento, 2011. Vol. I, p. 41-53.

MASSINI-CAGLIARI, G. Inovação Científica em Estudos Medievais: Descobrindo os sons do Português Arcaico. Revista da Anpol/Vol. 1, n³4, p. 17-50, Florianópolis, Jan./Jun. 2013.

MASSINI-CAGLIARI, G. A música da fala dos trovadores. Desvendando a prosódia medieval. São Paulo: Editora Unesp, 2015.

MASSINI-CAGLIARI. G. O papel da relação entre letra e música na investigação de elementos prosódicos em períodos passados da língua: análise de duas Cantigas de Santa Maria. In: CARRILHO, E.; MARTINS, A. M.; PEREIRA 
S.; SILVESTRE, J. P. (Org.) Estudos Linguísticos e Filológicos Oferecidos a Ivo Castro. Lisboa: Centro de Linguística da Universidade de Lisboa, 2019. p. 805-830.

METTMANN, W. (Ed.). Cantigas de Santa María (cantigas 1 a 100): Alfonso X, el Sabio. Madrid: Castalia, 1986.

NESPOR, M.; VOGEL, I. Prosodic Phonology. Dordrecht: Foris Publications, 1986.

PARKINSON, S. As Cantigas de Santa Maria. estado das cuestións textuais. Anvario de estudios literarios galegos, Vigo, p. 179-205, 1998.

PARKINSON, S. (Ed.) Alfonso X, the Learned. Cantigas de Santa Maria. An Anthology. Cambridge: The Modern Humanities Research Association, 2015.

RAPOSO DE MEDEIROS, B. Descrição comparativa de aspectos fonético-acústicos selecionados da fala e do canto em português brasileiro. Tese (Doutorado em Linguística). IEL, Unicamp, Campinas, 2002.

RAPOSO de MEDEIROS, B. Em busca do som perdido: o que há entre a Linguística e a Música. In: Beatriz Senoi llari. (Org.). Em busca da mente musical. 1ed.Curitiba: Editora da UFPR, 2006, v. 1, p. 1-451.

RAPOSO de MEDEIROS, B. Towards a Musical Gesture in the Perspective of Music as a Dynamical System. In: 12th International Conference on Music Perception and Cognition, 2012, Thessaloniki. Proceedings of the 12th International Conference on Music Perception and Cognition, 2012. v. 1. p. 843-847.

RAPOSO de MEDEIROS, B.; CABRAL, J . Acoustic distinctions between speech and singing: Is singing acoustically more stable than speech?. In: 9th International Conference on Speech Prosody 2018, 2018, Poznan. 9th International Conference on Speech Prosody 2018. ISCA: ISCA, 2018. p. 542-546.

RAPOSO de MEDEIROS, B.; CUMMINS, F. Speech and song synchronization: a comparative study. In: Seventh international conference on Speech Prosody, 2014, Dublin. Proceedings of the Seventh international conference on Speech Prosody. Dublin: Science Foundation Ireland, 2014. p. 748-752.

ROSSELL, A. Les Cantigas de Santa Maria: stratégie et composition, de l'élement métrique à l'élément idéologique. L'espace /yrique méditerranéen au Moyen Âge. Nouvelles approches, éd. par D. Billy, F. Clément et A. Combes, Toulouse: Presses Universitaires du Mirail, 2006. p. 231-250.

SELKIRK, E. O. On prosodic structure and its relation to syntactic structure. Indiana: IULC, 1980.

SELKIRK, E. O. Phonology and Syntax. Cambridge, Mass.: MIT Press, 1984.

SOUZA, A. R. de. A intenção na melodia: estudo interdisciplinar sobre as relações entre entoação e gênero do discurso nas manifestaçóes vocais (da fala ao canto). Tese (Doutorado em Filologia e Língua Portuguesa). FFLCH, USP, São Paulo, 2014.

TATIT, L. Semiótica da canção: melodia e letra. $3^{a}$ edição. São Paulo: Editora Escuta, 2007.

TATIT, L.; LOPES, I. Elos de melodia e letra. análise semiótica de seis canções. Cotia: Ateliê Editorial, 2008.

TENANI, L. E. Domínios prosódicos no Português do Brasil: Implicações para a prosódia e para a aplicação de processos fonológicos. Tese (Doutorado em Linguística) IEL, Unicamp, Campinas, 2002.

VERLUYTEN, S. P. M. (1982) Recherches sur la prosodie et la métrique du Français. Tese (Doutorado em Lingüística) Universitaire Instelling Antwerpen, Wilrijk,1982.

VIGÁRIO, M. The Prosodic Word in European Portuguese. PhD Dissertation. Lisbon: University of Lisbon, 2001.

ZUCARELLI, F. E. Ditongos e Hiatos nas Cantigas Medievais Portuguesas. Araraquara: FCL/UNESP. Dissertação de Mestrado (Linguística e Língua Portuguesa), 2002. 